\title{
Solving the Conflict Between Accessibility and Patent Protection of Drugs Based on Public Safety
}

\author{
Chunming $\mathrm{Xu}^{1}$, Debao $\mathrm{Zhu}^{2 *}$ \\ ${ }^{1}$ Law School, Shanghai University, Shanghai 200444, China \\ ${ }^{2}$ School of Management, Shanghai University, Shanghai 200444, China
}

Corresponding Author Email: zhudebao@shu.edu.cn

https://doi.org/10.18280/ijsse.100209

Received: 10 October 2019

Accepted: 5 January 2020

\section{Keywords:}

accessibility of drugs, patent rights of drugs, excess profits tax (EPT), master-slave game

\begin{abstract}
The patent system is a double-edged sword: for the pharmaceutical industry, the system stimulates the innovation of R\&D subjects, and effectively protects the drugs; for the public, the system facilitates the monopoly of pharmaceutical giants, pushing up the prices of patented drugs. Hence, the patent system results in the conflict between accessibility and patent protection of drugs. This paper explains the necessity of the patent system, identifies the problem of excessively high drug prices induced by patent monopoly, and proposes to regulate drug prices by levying the excess profits tax (EPT). Moreover, the master-slave game model was introduced to quantify the decision-making behaviors of the government and the pharmaceutical enterprise. The results show that the patent system can stimulate innovation in the pharmaceutical industry; as an auxiliary means, a reasonable EPT helps to regulate the prices of patented drugs; a suitable tax burden makes up for the lack of market regulation, and corrects the public losses induced by the monopoly of patent rights, thereby mitigating the conflict between accessibility and patent protection of drugs and enhancing the overall social welfare. The research findings shed new light on government regulation of the pharmaceutical industry.
\end{abstract}

\section{INTRODUCTION}

Our world is now plagued by many deadly diseases. To cure these diseases, technical innovation in drug development is badly needed, in addition to active prevention and control [1]. Innovation can be promoted by the patent system. Facing high R\&D costs and high risks, the pharmaceutical industry naturally has strong knowledge spillover and low technical complexity $[2,3]$. The drugs must be effectively protected by patents, such that R\&D subjects could make continuous innovations. However, patent protection often makes drugs less accessible, which harms public safety.

The accessibility of drugs is measured by whether patients can obtain proper, high-quality, and culturally-acceptable drugs safely and practically at affordable prices, and easily acquire the information about the rational use of drugs. Currently, the accessibility of drugs is mainly affected by two factors: whether drugs are available for specific diseases, and whether patients can afford the drug prices. The former depends on the technical level of the pharmaceutical industry, which calls for strong patent protection of drugs. Nonetheless, the monopoly endorsed by patent rights pushes up the prices of patented drugs, making them unaffordable and less accessible. What is worse, the mandatory standards of intellectual property protection, which are dominated by developed countries, have further consolidated the monopoly of pharmaceutical giants, and exacerbated the global public health crisis $[4,5]$.

The accessibility of drugs and public health will be impaired, whether the patent rights of a drug are monopolized by pharmaceutical giants or too dispersed to be implemented or to be transaction at a low cost $[2,4]$. In view of public interest, all countries agree that the prices of patented drugs in the free market should be regulated by stable policies. In Europe, the monopoly rights of pharmaceutical enterprises are directly restricted through price regulation [6]. For example, the UK designed the Pharmaceutical Price Regulation Scheme (PPRS) to limit the profits of pharmaceutical enterprises, after strict cost-benefit analysis [7]. Compared with the US, the UK has successfully control drug prices (Table 1). Based on costbenefit analysis, some scholars [8] put forward patientcentered pricing plans, where the pricing benchmark is treatment effect rather than production cost. However, these plans have greatly slowed down the speed of new drugs to reach the market.

Mindful of public interest, India never grants patent to medical inventions, and opposes profiteering at the cost of the rights of life and health. The Indian government relies on compulsory license to provide its citizens with reliable and stable drug prices $[9,10]$. In fact, many developing countries, namely, China, Brazil, and Mexico, guarantee the accessibility of drugs by compulsory license. Admittedly, compulsory license can alleviate the public health crisis to a certain extent. Nonetheless, there are several inevitable damages of compulsory license: the pharmaceutical enterprises will lose profits, the R\&D subjects will be less enthusiastic about innovation, and fewer new drugs will enter the market. All these damages are detrimental to the long-term interest of patients [11-13]. 
Table 1. Comparison of drug prices in the US and the UK

\begin{tabular}{ccccc}
\hline No. & $\begin{array}{c}\text { Name of } \\
\text { drug }\end{array}$ & $\begin{array}{c}\text { Price } \\
\text { (US) }\end{array}$ & $\begin{array}{c}\text { Price } \\
(\mathbf{U K})\end{array}$ & Unit \\
\hline 1 & Actimmune & $\$ 52,321$ & $\$ 6,897$ & 12 vials \\
2 & Daraprim & $\$ 99$ & $\$ 67$ & 100 tablets \\
3 & Cinryze & $\$ 44,140$ & $\$ 34,293$ & 20 vials \\
4 & Chenodal & $\$ 42,570$ & $\$ 16,160$ & 90 tablets \\
5 & Juxtapid & $\$ 36,992$ & $\$ 14,836$ & 30 capsules \\
6 & Firazyr & $\$ 32,468$ & $\$ 3,597$ & 2 syringes \\
7 & Harvoni & $\$ 31,500$ & $\$ 12,561$ & 21 tablets \\
8 & Cuprimine & $\$ 31,426$ & $\$ 150.84$ & 120 \\
capsules
\end{tabular}

Data source: https://www.pharmaceutical-technology.com/features/us-mostexpensive-drugs-uk-prices/

Parallel import is another way to ease the conflict between drug accessibility and patent protection [14]. At present, parallel import is mainly supported by two theories: exhaustion of right and implied license. For instance, Japan and most countries in Europe and North America adopt the principle of implied license for parallel import, in an attempt to promote the import of advanced techniques and products [15-17].

Some studies have shown that patented drug enterprises can fully exploit the potential market and maximize their profits, after finding the set of optimal prices across markets through differential pricing. This strategy is backed up by price discrimination and Ramsey pricing theory $[18,19]$. In practice, however, monopolists with core patents rarely adopt differential pricing, due to the following reasons: lowering the drug prices for the low-income group may encroach the market of high-priced drugs within a country and beyond; patented drug enterprises have higher costs than generic drug enterprises; the mass provision of drugs to the low- and middle-income groups requires additional investment in manufacturing capacity with uncertain return on investment (ROI) [20, 21].

Tax instruments are good options to control prices and protect public welfare. For example, Japan and South Korea have implemented real estate tax as a macro-control measure [22]. Multiple tax rates are designed to regulate the housing prices, and standardize the real estate market. Through constant improvements, the real estate tax system acquires the ability of self-stabilization, and the function of offsetting the macroeconomic problems brought by fluctuating housing prices [23].

In this paper, the excessively high prices of patented drugs are examined from the perspective of the government. Based on the current patent system, a tax instrument, i.e. excess profits tax (EPT), was designed for the sales of patented drugs, aiming to mitigate the conflict between accessibility and patent protection of drugs. Compared with property taxes like real estate tax, the EPT is a commodity tax, which can be calculated and collected without considering the various complex situations of taxpayers. The EPT can be levied at a simple proportional rate, making it easier to implement than real estate tax. The main innovations of this paper are as follows:

(1) The master-slave game model was introduced to describe the decision-making behaviors of the government and the pharmaceutical enterprise, and to fully analyze the interaction and mutual restraint between the government department that designs the EPT and the pharmaceutical enterprise that sets drug prices.

(2) The tax rate, optimized by the two-layer nonlinear programming model, which is based on the master-slave game model, mitigates the public safety crisis, and promotes the overall social welfare, while ensuring that the pharmaceutical enterprise is enthusiastic about innovation.

The remainder of this paper is organized as follows: Section 2 establishes a master-slave model to describe the decisionmaking behaviors of the government and the pharmaceutical enterprise under the EPT; Section 3 solves the established model, determines the optimal tax rate, and analyzes the obtained results; Section 4 puts forward the conclusions and looks forward to the future research.

\section{MODELLING}

\subsection{Background and hypotheses}

The conflict between accessibility and patent protection of drugs cannot be solved in the profit-seeking free market. The government is obliged to formulate the right policies to guide the healthy development of the pharmaceutical industry. These policies should, on the one hand, safeguard the public interest of drug use and promote the accessibility of drugs, and, on the other hand, fully incentivize the R\&D subjects to pursue continuous innovation.

This paper attempts to control the excessive drug prices by regulating the tax burden of pharmaceutical enterprises with the EPT. The enterprise decisions on the EPT will react upon the government. Thus, the enterprise and the government will restrain each other. This is a typical multi-party interest optimization problem. The interaction between government and enterprise could be described by the master-slave game model.

The government, as the master of the master-slave model, makes decisions before the pharmaceutical enterprise. The two parties should solve the following problems through the game:

(1) What is the premium ratio to start levying the EPT, and what is the optimal tax rate in terms of patient satisfaction?

(2) Under the EPT, how should the pharmaceutical enterprise maximize its interests through drug pricing and production planning?

The basic hypotheses of the master-slave model are as follows:

Table 2. Parameters of the master-slave model

\begin{tabular}{cccc}
\hline Parameter & Meaning & Parameter & Meaning \\
\hline$y$ & Drug output in the research period & $E_{0}$ & Net income of pharmaceutical enterprise \\
$c$ & Unit drug cost (incl. R\&D cost) & $E_{1}$ & Gross income of pharmaceutical enterprise \\
$p$ & Drug price & $E_{2}$ & Taxable income \\
$a$ & Premium ratio (decision variable) & $s$ & Patient satisfaction (rated against a 100-point scale) \\
$t$ & EPT rate (decision variable) & $\beta_{i}$ & Weighted average coefficient $(i=1,2)$ \\
$u_{i}$ & Lagrange multiplier $(i=1,2,3,4,5)$ & & \\
\hline
\end{tabular}


(1) The EPT is levied with a known threshold at a fixed rate.

(2) The research period equals the valid period of the core compound of the patented drug, without considering the market state after the patent expires.

(3) Only one patented pharmaceutical enterprise is considered in the model.

(4) The drug price is negatively correlated with drug output and patient satisfaction.

(5) The tax rate is positively correlated with the excess profits.

The parameters of the master-slave model are explained in Table 2 above.

\subsection{Modelling}

\subsubsection{Slave (pharmaceutical enterprise)}

In the research period, it is assumed that the market demand equals the drug output $y$, and the relationship between drug price $p$ and drug output $y$ depend on the supply and demand in the market. In the model, the relationship between the two parameters is described by an inverse proportional function:

$$
p=f(y)=a_{1} / y \quad\left(a_{1}>0\right),
$$

where, $a_{l}$ is the proportionality coefficient.

The pharmaceutical enterprise pursues the maximum profits. Under the EPT, the net income $E_{0}$ of the enterprise is the difference between the gross income $E_{1}$ and the taxable income $E_{2}$ :

$$
E_{0}=E_{1}-E_{2} \cdot t
$$

The decision-making of the pharmaceutical enterprise is affected by the market demand, supply-demand relationship, and government tax policy. Hence, the optimization model of the salve can be defined as:

$$
\begin{gathered}
\max _{\alpha, y} E_{1}-E_{2} \cdot t \\
\text { s.t. } \quad p=f(y), \\
y=\log _{d} \alpha, \\
E_{1}=(\alpha-1) \cdot c \cdot y, \\
E_{2}= \begin{cases}0, & \text { other } \\
E_{1}-E_{0,} & \text { if } \quad E_{1}>E_{0}, \text { and } \alpha>2\end{cases} \\
\alpha \geq 1, \quad c \geq 0, \quad 0 \leq t \leq 1 .
\end{gathered}
$$

where, formula (3) is the objective function representing the maximum income of the pharmaceutical enterprises under constraints; formula (4) is the relationship between drug price and drug output; formula (5) is the market constraint on the output of the patented drug in the research period; formulas (6) and (7) reflect the relationship between taxable income $E_{2}$ and premium ratio $a$, i.e. how the EPT influences drug pricing. If the price is too high, the enterprise will lose a portion of market to generic drug enterprises, increasing its tax burden.

\subsubsection{Master (government)}

To model the decision-making of the government, patient satisfaction $s$ was rated against a 100-point scale. The weighted average $\beta$ of patient satisfaction $s$ and the tax income was calculated, and taken as the optimization objective of the master. The relationship between patient satisfaction $s$ and drug price $p$ is described by an inverse proportional function

$$
s=g(p)=a_{2} / p \quad\left(a_{2}>0\right)
$$

Based on the EPT rate $t$, the tax income of the government can be obtained as $E_{2} \cdot t$. There is a certain correlation between the taxable income $E_{2}$ and the EPT rate $t$. In the general practice of taxation, the tax rate should increase with the income. Hence, the relationship between the EPT rate $t$ and the taxable income $E_{2}$ should satisfy:

$$
t=h\left(E_{2}\right)=k_{1} \cdot E_{2} \quad\left(k_{2} \geq 0\right),
$$

The government must put public health first, i.e. make public satisfaction of drug price as the top priority. Therefore, the objective function of the government can be established as:

$$
\max _{\alpha, t, y} \beta_{1} s+\beta_{2} E_{2} t
$$

To sum up, the decision-making behaviors of the government and the pharmaceutical enterprise under the EPT can be described by the following two-layer model:

$$
\begin{aligned}
& \text { Master's decision-making model } \\
& \left\{\begin{array}{l}
\max _{\alpha, t, y} \beta_{1} s+\beta_{2} E_{2} t \\
s . t . \\
s=g(p), \\
t=h\left(E_{2}\right), \\
y=\log _{d} \alpha, \\
E_{1}=(\alpha-1) \cdot c \cdot y, \\
E_{2}=\left\{\begin{array}{l}
0, \quad \text { other conditions } \\
E_{1}-E_{0,} \text { if } E_{1}>E_{0}, \text { and } \alpha>2
\end{array}\right. \\
\beta_{1}+\beta_{2}=1, \quad 0, \\
0 \leq \beta_{1} \leq 1, \quad 0 \leq \beta_{2} \leq 1 .
\end{array},\right. \\
& \text { Slave's decision-making model } \\
& \left\{\begin{array}{l}
\max _{\alpha, y} E_{1}-E_{2} \cdot t \\
\text { s.t. } \\
p=f(y), \\
y=\log _{d} \alpha, \\
E_{1}=(\alpha-1) \cdot c \cdot y, \\
E_{2}= \begin{cases}0, & \text { other conditions } \\
E_{1}-E_{0,} & \text { if } E_{1}>E_{0}, \text { and } \alpha>2\end{cases} \\
\alpha \geq 1, \quad c \geq 0, \quad 0 \leq t \leq 1 .
\end{array},\right.
\end{aligned}
$$

The above two-layer model shows that the government's decision-making is bounded by drug price and taxable income, and that drug price directly depends on patient satisfaction. The two parties of the game must pursue their own best interests, without hitting the bottom line of the other party. 
During the game, the government should determine the taxable income $E_{2}$ through an extensive social survey, and then set a suitable tax threshold. If the $E_{2}$ is too high, the pharmaceutical enterprise will be less enthusiast about R\&D; the innovation of drugs and relevant techniques will be hindered, harming the interests of the whole society. If the $E_{2}$ is too low, the drug prices cannot be controlled to improve patient welfare, and the promoting effect on fiscal revenue will be very limited. Similarly, the tax rate $t$ should also be determined carefully.

Note that our two-layer model does not consider whether the enterprise will leave the market in the face of stringent tax policy. To circumvent this factor, the initial values of our model were selected and optimized based on the situation of the actual market, such as to enhance the feasibility of our model.

The two-layer master-slave game model was subjected to equivalent transform of Karush-Kuhn-Tucker (KKT) conditions. If $E_{1} \geq E_{0}$ and $\alpha \geq 2$, the transformed model can be expressed as:

$$
\begin{aligned}
& \max _{\alpha, t, y, u_{1}, u_{2}, u_{3}, u_{4}, u_{5}} \beta_{1} s+\beta_{2}\left[(\alpha-1) c y-E_{0}\right] t \\
& \text { s.t. } \\
& s=g(p), \\
& t=h\left(E_{2}\right), \\
& \beta_{1}+\beta_{2}=1, \\
& 0 \leq \beta_{1} \leq 1, \quad 0 \leq \beta_{2} \leq 1, \\
& -\alpha c y+\alpha c y t-u_{3}-u_{4} c y=0, \\
& \nabla_{\alpha} L=(\alpha-1) c+(\alpha-1) c t-u_{5}, \\
& 0 \leq u_{1} \perp t \geq 0 \\
& 0 \leq u_{2} \perp 1-t \geq 0 \\
& 0 \leq u_{3} \perp \alpha-2 \geq 0, \\
& 0 \leq u_{4} \perp(\alpha-1) c y-E_{0} \geq 0, \\
& 0 \leq u_{5} \perp y \geq 0 .
\end{aligned}
$$

With the aid of the personal health record (PHR) algorithm, the above model was solved on MATLAB 2016a.

\section{RESULTS AND DISCUSSION}

\subsection{Results}

Although the Chinese government has laid down regulations on pricing of drugs, the drug prices increase through the layers of the supply chain. The drug prices paid by patients are about 5 to 10 times the ex-factory prices. The prices of patented drugs are often 4 to 12 times those of common drugs. The excessive premium seriously undermines the accessibility of relevant drugs, and dampens patient satisfaction. Therefore, the government is obliged to control the prices of patented drugs, improve patient satisfaction, and promote social welfare.

In our master-slave game, the government mainly aims to control drug prices, improve patient satisfaction, and maximize overall social welfare, while the enterprise pursues the maximum profits. As shown in Figure 1, patient satisfaction hinges on premium ratio $\alpha$ and drug output $y$, both of which are regulated by the government through the tax rate.

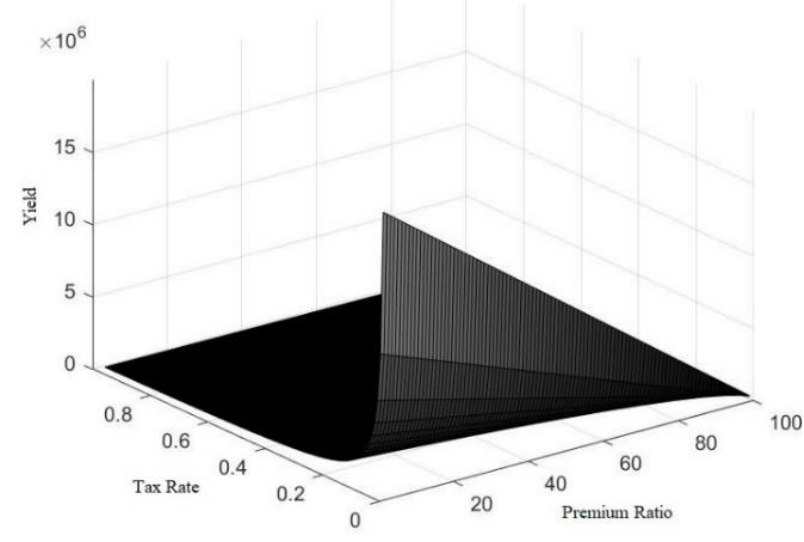

Figure 1. Influence of tax rate on premium ratio and drug output

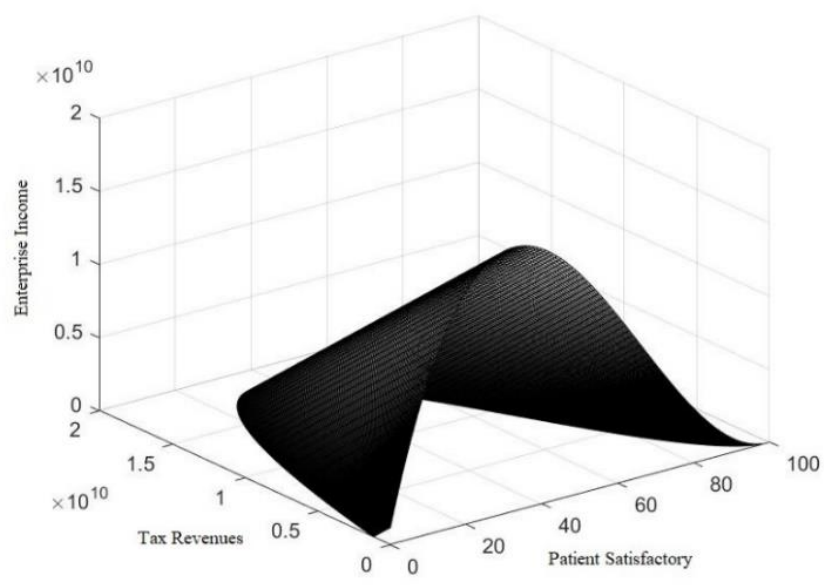

Figure 2. Correlation of patient satisfaction with enterprise income and tax revenues

As shown in Figures 1, a high tax rate is not necessarily good. If the tax rate is too high, the enterprise will be unenthusiastic about production in the short term, and reluctant to invest in $R \& D$ in the long run. Thus, the tax rate should be designed in the light of enterprise income, and incentivize the $R \& D$ of the enterprise.

The enterprise income mainly relies on premium ratio $\alpha$ and drug output y. According to the supply-demand relationship in the market, the output of patented drugs increases first and then declines, with the growing premium ratio. In our model, the relationship between premium ratio $\alpha$ and drug output $y$ can be fitted as:

$$
y=\left(-\alpha \times 10^{4}+1.01 \times 10^{6}\right) \times 0.2 \alpha
$$

The relationship between patient satisfaction, tax revenues, and enterprise income is as shown in Figure 2. Finally, the equilibrium solution could be obtained as: the optimal tax rate $t=22.7 \%$. In this case, the premium ratio of patented drugs $\alpha=8.8145$, and patient satisfaction was 91.1855 . This means a reasonable tax policy can realize the following three goals at the same time: effective control of the prices of patented drugs, improve drug accessibility, and ensure enterprise income. 


\subsection{Discussion}

The accessibility of drugs is affected by multiple factors. The foregoing analysis shows that the accessibility of drugs can be improved through continuous innovation in the pharmaceutical industry, and keeping the prices of patented drugs at a reasonable level. To stimulate innovation, the government could establish a patent law system to protect monopoly rights; to keep reasonable prices, the government could regulate drug pricing with tax burden. Based on the model results, the mechanism of these policy tools was discussed in details.

\subsubsection{Slave (pharmaceutical enterprise)}

First, the optimization objective of the pharmaceutical enterprise is to maximize its profits. Without considering the impact of generic drug market, the enterprise always benefits from high premium and low tax rate. The fundamental reason for the enterprise to maintain a high premium lies in the monopoly rights grants by the patent system.

In the pharmaceutical industry, the cycle of a new drug lasts over 10 years, from $\mathrm{R} \& \mathrm{D}$, clinical test, to marketing. The numerous uncertainties in the cycle make innovation rather risky. Through patent protection, the government promises high returns, usually monopoly profits, to the pharmaceutical enterprise, encouraging the latter to make technical innovation under risk. This measure caters to the psychology of the pharmaceutical enterprise: pharmaceutical technologies are not complex, and thus easy to be imitated at a low cost [2427]. Therefore, the pharmaceutical enterprise prefers to protect innovation through patent disclosure, rather than keep technical secrets.

However, the pharmaceutical enterprise is profit-seeking. During the pricing of patented drugs, the enterprise tends to increase the premium ratio and expand production capacity. With the increase of premium, the profit per unit of product rises. Then, the enterprise is more motivated to expand the production capacity. But when the premium ratio rises to a threshold, the enterprise will face a higher tax burden: the government will control the excessive drug price with the EPT. Under the EPT, the benefit of raising the premium ratio will be overshadowed by the tax pressure, leading to the loss of patient market.

The patients' access to drugs mainly hinges on drug prices. Excessive drug prices will affect the sales of drugs, which in turn lowers the overall revenue of the pharmaceutical enterprise. Hence, the output of patented drugs tends to decline at a high premium.

As the premium ratio $\alpha$ increases and the tax rate $t$ decreases, the enterprise profits continue to grow, so does its production capacity. The burden of high tax could be transferred to patients by elevating the premium ratio. In this way, the overall profits of the enterprise are on the rise. However, the tax burden increases linearly with the tax rate $t$. Even if the premium ratio $\alpha$ could be further increased, the enterprise will face a shrinking profit margin per unit of drugs, and a dwindling potential for profit increase.

Under the effects of tax rate and premium ratio, the optimal solutions of enterprise profits (positively correlated with output) concentrate in the region of high premium and low tax rate. But as mentioned above, excessive drug prices will narrow down the patients' access to drugs, causing the pharmaceutical enterprise to lose part of its patented drug market to generic drug enterprises. In other words, excessively high prices are an indirect cause of profit loss. Compared to those in the free market, the prices of patented drugs will be controlled to a certain extent under the EPT, for the enterprise needs to consider both drug profits and patient market.

\subsubsection{Master (government)}

As mentioned earlier, the patent protection of drugs leads to two problems, although it could effectively stimulate innovation: (1) The patent law lacks an effectively regulation mechanism for the drug market. Without no restriction on the monopoly rights, the pharmaceutical enterprise will recklessly increase drug prices, which infringes on the public interests of drug use and lowers the accessibility to drugs. (2) The profitseeking nature determines that the enterprise lacks the motivation to maintain public interests. Since the enterprise always pursues the maximal profits, the prices of patented drugs will always be too high in the monopoly market. To solve the problems, the government is responsible to protect the patients' rights of drug use and improve the accessibility of drugs.

For patients, the accessibility to drugs is measured by the availability and affordability of drugs. For pharmaceutical enterprise, the profits are directly influenced by the sales and unit price of drugs. The patients' goal of drug availability is consistent with the enterprise's pursuit of drug sales, but the patients' goal of drug affordability conflicts with the enterprise's pursuit of high unit price of drugs.

The premium has a positive effect on the enthusiasm of the enterprise in drug development and production. If the principal contradiction lies between the patients' goal of drug availability and the zero or short supply of drugs, the enterprise will make great profits if it pioneers in the $\mathrm{R} \& \mathrm{D}$, production, and marketing of drugs. Despite the high drug prices, the rights to life and health of some patients could be guaranteed. Overall, the enterprise and the patients benefit each other, and the accessibility of drugs is improved.

With the development of technology and economy, the main contradiction changes into the conflict between the patients' urgent need of drugs and the low affordability of high-price drugs. In this case, the government's tax policy starts to take effect.

Under a low tax rate, patient satisfaction covers almost the entire range of $0-100$. At this time, the tax policy fails to achieve the expected results. Patient satisfaction is mainly affected by premium ratio and innovation ability of the pharmaceutical enterprise. The highest patient satisfaction appears under low premium ratio and high R\&D investment. These conditions are so strict to the enterprise as to be unrealistic. Under these conditions, the equilibrium state goes as follows: the enterprise reaps monopoly profits with high premium ratio, and partially damages the interests of public health.

Under a high tax rate, the patient satisfaction is only about 30. The main reason is as follows: although the drug prices are controlled well, the profits are too low, i.e. the enterprise fails to receive the expected return from the R\&D investment. The economic loss is so severe that the enterprise is unable to invest more in R\&D. Therefore, the interests of public health are undermined indirectly, making it difficult to improve patient satisfaction.

Therefore, the government, despite being the upper-level decision maker, is jointly restrained by the pharmaceutical enterprise and patients. The blind setting of high tax rates will sacrifice the long-term interests of patients. As a result, the 
government's tax policy must target both the existing problems, and the future development of the medical field. In the event of market failure, the government should intervene in the market with a reasonable tax policy, aiming to correct the public losses caused by the monopoly of the pharmaceutical enterprise, while ensuring that patent holders are fully incentivized. In this way, the government could protect the vulnerable group of patients, and overcome the prejudice of one-sided fairness. This kind of intervention respects the basic laws of the market, promotes the fairness and reasonability of the pharmaceutical market, and benefits the sustainable development of technology and economy.

\section{CONCLUSIONS}

This paper explores the conflict between the accessibility and patent protection of drugs, and analyzes the necessity of patent protection to stimulate innovation. Facing the excessively high prices of patented drugs, the authors suggested levying the EPT to help mitigate the failure of market regulation in patented drugs, making the drugs more accessible. The master-slave game model was introduced to illustrate the interest relationship between the government and the pharmaceutical enterprise. The relevant optimization functions were established to obtain a solution that balance the interests of patients and those of the enterprise.

Patent protection, a necessary condition for improving the accessibility of drugs, guarantees technical innovation at the level of patent law system. The guarantee will push up the prices of patented drugs, which should be regulated by the government. Reasonable tax burden offers the government an effective means to regulate drug prices. The proposed EPT is a simple and efficient instrument that directly acts on the income of the pharmaceutical enterprise. The influence mechanism of the EPT on the decision-making of the enterprise is as follows: Under the EPT, the burden of high tax could be transferred to patients by elevating the premium ratio, but the blind increase of drug prices will cause market loss and reduce the total income of the enterprise. Therefore, the enterprise has the motive to control drug prices. Meanwhile, the government should carefully design the tax rate to solve the conflict between drug accessibility and patent protection. The patents' right of drug use and the enterprise' enthusiasm of innovation must be balanced to improve the overall social welfare.

Compared with traditional methods (e.g. compulsory licensing), our tax instrument fully supplements the existing patent system, and effectively regulates the conflict between the accessibility and patent protection of drugs. Of course, there are several limitations of our research: (1) For simplicity, several factors were neglected in the modelling process, namely, the impact of generic drug enterprises, medical insurance subsidies, and alternative treatment plans; (2) There is insufficient data for verification and analysis, adding to the difficulty in model improvement. Overall, our model is still a realistic demonstration of the game between the government and the pharmaceutical enterprise, and a mirror of the functions of tax instrument in coordinating drug accessibility and drug patent protection. Our research results provide reference for the formulation of relevant policies.

\section{REFERENCES}

[1] Wang, C., Horby, P.W, Hayden, F.G., Gao, G.F. (2020). A novel coronavirus outbreak of global health concern. The Lancet, 395(10223): 470-473. https://doi.org/10.1016/S0140-6736(20)30185-9

[2] Von Graevenitz, G., Wagner, S., Harhoff, D. (2013). Incidence and growth of patent thickets: The impact of technological opportunities and complexity. The Journal of Industrial Economics, 61(3): 521-563. https://doi.org/10.1111/joie.12032

[3] Juneja, S., Gupta, A., Moon, S., Resch, S. (2017). Projected savings through public health voluntary licences of HIV drugs negotiated by the Medicines Patent Pool (MPP). PloS One, 12(5): e0177770. https://doi.org/10.1371/journal.pone.0177770

[4] Wirtz, V.J., Hogerzeil, H.V., Gray, A.L., Bigdeli, M., de Joncheere, C.P., Ewen, M.A., Möller, H. (2017). Essential medicines for universal health coverage. The Lancet, 389(10067): 403-476. https://doi.org/10.1016/S0140-6736(16)31599-9

[5] Chaudhuri, S. (2019). Are medicine prices high and unaffordable after TRIPS? Evidence from Pharmaceutical Industry in India. Commentary on India's Economy and Society Series, 1-42.

[6] Jeon, D.S., Lefouili, Y. (2018). Cross-licensing and competition. The RAND Journal of Economics, 49(3): 656-671. https://doi.org/10.1111/1756-2171.12248

[7] Webb, D.J., Walker, A. (2007). Value-based pricing of drugs in the UK. Lancet, 369(9571): 1415-1416.

[8] Koh, C.Y.C., Seager, T.P. (2017). Value-based pharmaceutical pricing from the patient perspective could incentivize innovation. Pharmaceutical Medicine, 31(3): 149-153. https://doi.org/10.1007/s40290-0170189-3

[9] Gandhi, B. (2019). India's compulsory license model: Increased pharmaceutical access and innovation coexist. Brigham Young University Prelaw Review, 33(1): 5.

[10] Bond, E., Saggi, K. (2019). Price controls versus compulsory licensing: Effects on patent-holders and consumers. The WTO and Economic Development, 2019: 303.

[11] Hu, J.X. (2016). On the construction of patent license of right system in China. Intellectual Property, (6): 12.

[12] Flynn, S., Hollis, A., Palmedo, M. (2009). An economic justification for open access to essential medicine patents in developing countries. The Journal of Law, Medicine \& Ethics, 37(2): 184-208. https://doi.org/10.1111/j.1748720X.2009.00365.X

[13] Vogler, S., Leopold, C., Zimmermann, N., Habl, C., de Joncheere, K. (2014). The pharmaceutical pricing and reimbursement information (PPRI) initiativeExperiences from engaging with pharmaceutical policy makers. Health Policy and Technology, 3(2): 139-148. https://doi.org/10.1016/j.hlpt.2014.01.001

[14] Brekke, K.R., Holmås, T.H., Straume, O.R. (2015). Price regulation and parallel imports of pharmaceuticals. Journal of Public Economics, 129: 92-105. https://doi.org/10.1016/j.jpubeco.2015.08.002

[15] Watal, J. (2017). III. 14 exhaustion of right sand parallel importation in intellectual property. Elgar Encyclopedia of International Economic Law. Edward Elgar Publishing, 2017: 375-377. https://doi.org/10.4337/9781784713546.192 
[16] Lai, J.C. (2018). The exhaustion of patent rights $v$ the implied licence approach: untangling the web of patent rights. Queen Mary Journal of Intellectual Property, 8(3): 209-230. https://doi.org/10.4337/qmjip.2018.03.03

[17] Nguyena, X., Chaoa, C.C., Hwangb, H. (2016). NorthSouth parallel import, trade liberalization and optimal taxation.

[18] Ramsey, F.P. (1927). A contribution to the theory of taxation. The Economic Journal, 37(145): 47-61. https://doi.org/10.2307/2222721

[19] Danzon, P.M. (2018). Differential pricing of pharmaceuticals: Theory, evidence and emerging issues. PharmacoEconomics, 36(12): 1395-1405. https://doi.org/10.1007/s40273-018-0696-4

[20] Danzon, P., Towse, A., Mestre-Ferrandiz, J. (2015). Value-based differential pricing: Efficient prices for drugs in a global context. Health Economics, 24(3): 294301. https://doi.org/10.1002/hec.3021

[21] Dean, E.B. (2017). Who Benefits from Pharmaceutical Price Ceilings? Evidence from India.

[22] Jeong, S., Choi, I. (2017). A study of the market reaction following the change of the real estate transfer tax policy- focus on the Korean real estate market. International Information Institute (Tokyo). Information, 20(3A): 1471-1478.

[23] Farle, V., Schmitt, R. (2017). German taxation of inbound real estate investments. Understanding German Real Estate Markets. Springer, Cham, 2017: 201-223. https://doi.org/10.1007/978-3-319-32031-1_15

[24] Sternitzke, C. (2013). An exploratory analysis of patent fencing in Pharmaceuticals: The case of PDE5 inhibitors. Research Policy, 42(2): 542-551. https://doi.org/10.1016/j.respol.2012.11.003

[25] Wu, W. (2018). Patent pool and deprivatization of patents. Asian Journal of Law and Economics, 9(3). https://doi.org/10.1515/ajle-2018-0016

[26] Von Graevenitz, G., Wagner, S., Harhoff, D. (2013). Incidence and growth of patent thickets: The impact of technological opportunities and complexity. The Journal of Industrial Economics, 61(3): 521-563. https://doi.org/10.1111/joie.12032

[27] Weimer, D.L., Vining, A.R. (2017). Policy analysis: Concepts and practice. Taylor \& Francis, 2017: 123. 